\title{
Two new Orthocladiinae (Diptera: Chironomidae) collected in overlooked places of Midwest USA
}

\author{
ARMIN NAMAYANDEH ${ }^{1 *} \&$ PATRICK L. HUDSON ${ }^{2}$ \\ ${ }^{1}$ Department of Environmental and Life Sciences, Trent University, 1600 West Bank Drive, Peterborough, ON, Canada. \\ "'arminnamayandeh@trentu.ca; "'a.namayan@taxanama.com; @ https://orcid.org/0000-0003-2136-0497 \\ 25597 New Meadow Drive, Ypsilanti, MI 48197. |" patrick_hudson@sbcglobal.net; @ https://orcid.org/0000-0002-7646-443X443X \\ ${ }^{*}$ Corresponding author
}

\begin{abstract}
We describe Cedrimyia margareti gen. nov., sp. nov. from Ohio and Wisconsin, and Parakiefferiella mishigami sp. nov. (Orthocladiinae) from Michigan. Cedrimyia is likely related to Antillocladius Sæther, 1981, Litocladius Mendes, Andersen and Sæther, 2004, Lyrocladius Mendes and Andersen, 2008, and Compterosmittia Sæther, 1981, genera with scalpellate acrostichals. The new species of Parakiefferiella has a well-separated bilobed inferior volsella differing in shape from known Parakiefferiella species.
\end{abstract}

Key words: Chironomidae, Orthocladiinae, new taxa, Nearctic, USA

\section{Introduction}

The Nearctic is the second diversity-rich geographical region for the family Chironomidae, holding 1092 species (Ferrington, 2008). The estimated number of species for the USA, however, has never been obtained. The only estimate of Chironomidae diversity in the USA with 479 species comes from Hudson et al. (1990), covering the Southeastern states. From the Midwest USA, Bolton (2012) lists 510 species from Ohio, USA, and Bright (2020) lists 305 species with at least another 247 species likely to occur in Michigan, USA. These being relatively well-studied in comparison to other Midwestern states. The reports of Chironomidae from Wisconsin, USA, are partial, with the most comprehensive account being from the Upper Saint Croix River by Egan and Ferrington (2019), reporting 252 species. No account of chironomid diversity is available from other Midwestern states to the best of our knowledge. The current study is produced as the outcome of a continuing review of the 15,000 specimens of chironomids in the USGS Great Lakes Science Center reference collection. These species were collected and or curated over the last 55 years by the second author. The two new taxa described below were collected in the Great Lakes Region and come from poorly collected environments, large rivers, and possible semi-terrestrial habitats. These new taxa will be added to our list of 500 or so chironomid species found in the Great Lakes proper and associated habitats such as wetlands, dunal ponds, river mouths, and other shoreline habitats.

This study describes Cedrimyia margareti gen. nov., sp. nov. from Ohio and Wisconsin, and Parakiefferiella mishigami sp. n. (Orthocladiinae) from Michigan based on their adult specimens. The Cedrimyia likely belongs to the group of genera with scalpellate acrostichals. Although, Cedrimyia adults collected in the vicinity of a creek, the larva is likely not truly aquatic, presumably inhabiting decaying moist organic matter. We collected the P. michigami adult male from the plankton nets set to collect fish larva. This new species of Parakiefferiella has a distinct bilobed inferior volsella which separates it from other Parakiefferiella species.

\section{Material and methods}

We found specimens of the new Parakiefferiella species in larval fish samples taken with an ichthyoplankton net 
in the St. Marys River, Michigan during May 1991. Specimens of the new genus Cedrimyia has aspirated off a pedestrian bridge rail crossing Queer Creek in Hocking Hills State Park, Ohio. The Wisconsin specimen of Cedrimyia was collected with a sweep net from a peninsula of land bordering Lake Superior, southeast of the Superior Entry into the Twin Ports of Duluth, Minnesota and Superior, Wisconsin.

We preserved the specimens in $70 \%$ ethanol in the field. In the laboratory, we placed the specimens in $95 \%$ ethanol for subsequent mounting. Adults were mounted in Euparal using a method developed by Patrick Hudson. We removed the wings, a pair of legs, and one antenna and mounted them in Euparal on a glass slide and covered with a coverslip. We placed the remaining material in $10 \%$ potassium hydroxide for around 24 hours. At that time, the body was placed in the acetic acid solution for approximately 10 minutes and then back into $95 \%$ ethanol. After 10 minutes or so, we dissected the specimens and mounted various parts in drops of Euparal on the glass slide. We placed the slides in a warm oven over days, and the additional layers of Euparal were placed on the thorax and abdomen to build up a suitable covering. After several days, we placed a small drop of Euparal on these two parts, and with the idea that the addition of this material would not soften and shift or crush the abdomen and thorax, we added a coverslip. We added small amounts of Euparal over many days to the slides until the underside of the coverslip was filled entirely with the mounting media. Mounted specimens were usually left to dry for weeks once the slides were deemed acceptable.

We produced the imagery using a Diagnostic Instruments Inc. Spot 5.1 camera mounted on an Olympus BX51 compound scope. All type and voucher specimens of Chironomidae deposited at the Albert J. Cook Arthropod Research Collection (ARC), Michigan State University. Voucher specimens of the new genus are housed in the Chironomid Reference Collection of USGS Great Lakes Science Center. Morphological terminology and measurements follow those of Sæther $(1977,1980)$.

\section{Taxonomy}

\section{Genus Cedrimyia gen. nov.}

Figs. $1-2$

LSID: urn:1sid:zoobank.org:act:7845E8DA-9E57-427D-80C5-BEE7B922A672

Type species. Cedrimyia margareti Namayandeh and Hudson, sp. n. by present designation.

Diagnostic characters. A combination of eyes with wedge-shaped dorsomedial extension; presence of 2 scalpellate acrostichals in centre of scutum; anterpronotal lobes without gap; tergite IX with curved ridge running close to mid-section of anal point; anal point long, bearing simple, short and weak setae, pointing posteriorly; virga consisting of two long spines; gonostylus with strong, comparatively darker spine-like setae; crista dorsalis thin and blade-like, stretching from mid to anterior of gonostylus separates Cedrimyia from most Orthocladiinae (see also the remarks section).

Etymology. The new genus is named after its type locality, Cedar Falls in Ohio. The suffix "myia" is Greek for the fly.

Description. Adult male. Small to medium size species up to $3.2 \mathrm{~mm}$ long. Wings up to $2.3 \mathrm{~mm}$ long.

Head (Fig. 1a). Antenna with 12 flagellomeres, $2^{\text {nd }}-3^{\text {rd }}$ segments and last flagellomere with sensilla chaetica. Eyes bare, with wedge-shaped dorsomedial extension. Temporal setae present, including inner verticals, postoculars and outer verticals. Tentorium narrow with small tentorial pit close to apex. Clypeus rectangular. Palp 5 segmented with third palpomere having sensilla clavata.

Thorax (Fig. 1b). 2 scalpellate acrostichals in centre of scutum. Dorsocentrals in single row, prealars few, scutellars in single row. Humeral pit small. Antepronotal lobes developed, narrowing anteriorly, without gap and bare.

Wing (Fig. 1c). Brachiolum, squama and $\mathrm{R}$ with setae. Other veins without setae. Costa extended. $\mathrm{R}_{4+5}$ ends just above $\mathrm{M}_{3+4}$. Anal lobe squared. Microtrichia visible at $>100 \mathrm{x}$ magnification.

Legs. Mid and hind tibia with long sparse beard, hind femur with keel. Pulvilli absent. Fore tibia with 1 spur, each of mid and hind tibia with 2 spurs. Hind tibia comb developed.

Hypopygium (Fig. 1d). Tergite IX with curved ridge running close to mid-section of anal point. Anal point narrowly triangular, long, reaching close to the apex of inferior volsella, bearing simple, short, and weak setae, distributed evenly along its mid-section, and pointing posteriorly, apex rounded. Virga present consists of two long 
spines. Sternapodeme straight and thick. Phallapodeme collar bone-shaped. Inferior volsella a prominent triangular lobe. Gonostylus squat-shaped, well expanded in mid to anterior section, surface with strong, comparatively darker, spine-like setae; crista dorsalis developed, thin and blade-like, stretching from mid to anterior of gonostylus.

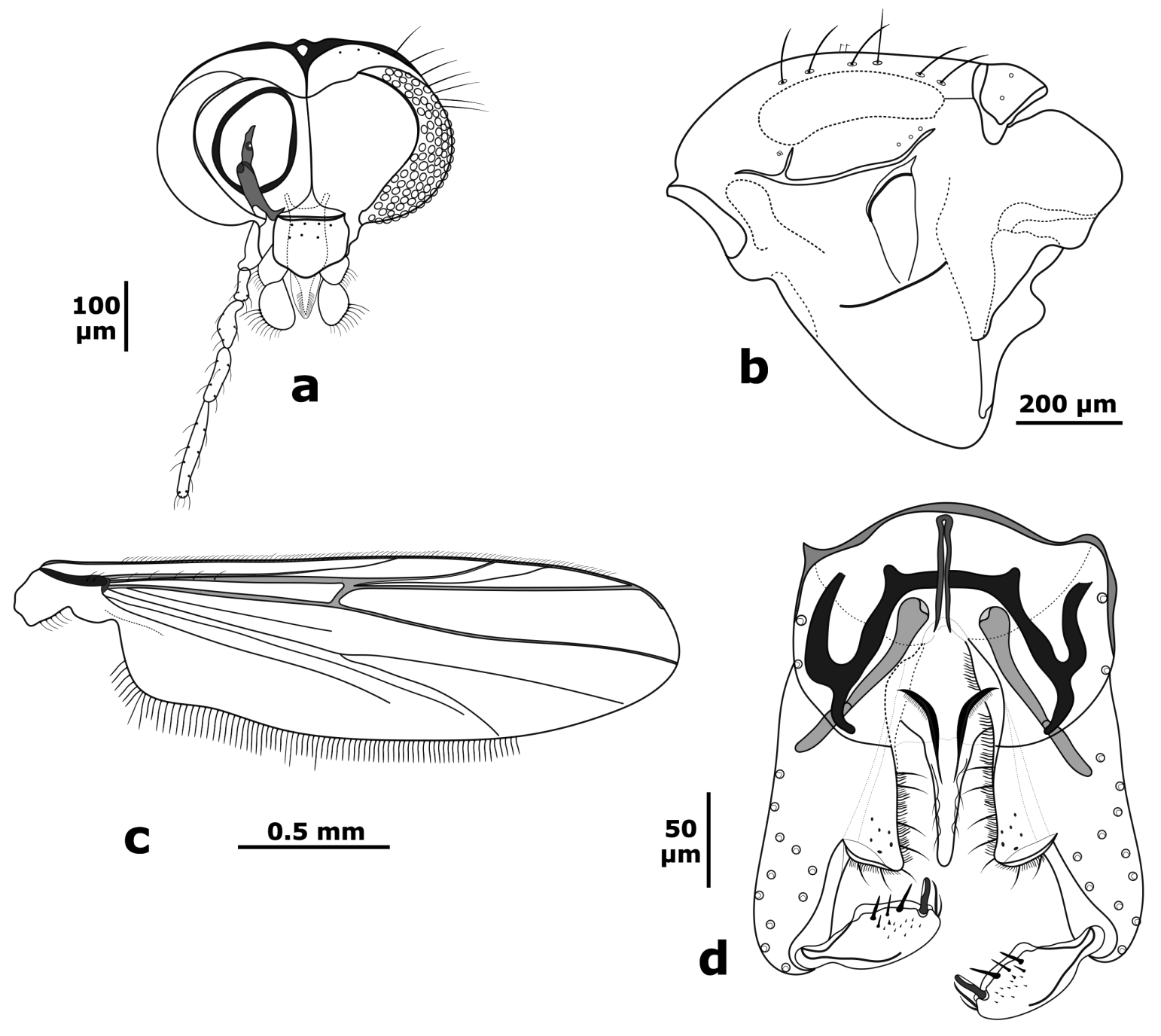

FIGURE 1. Cedrimyia margareti gen. n. sp. n., male. a. head; b. thorax; c. wing; d. hypopygium.

Adult female. Small species up to $2.1 \mathrm{~mm}$ long. Wing up to $2.4 \mathrm{~mm}$ long.

Head (Fig. 2a-b). Antenna with 5 flagellomeres, $3^{\text {rd }}-4^{\text {th }}$ segments and last flagellomere with sensilla chaetica. Eyes bare, with short dorsomedial extension. Temporal setae present, including inner verticals, postoculars, orbitals and outer verticals. Tentorium long and narrow with small tentorial pit close to apex. Clypeus rectangular. Palp 5 segmented with third segment bearing sensilla clavata.

Thorax. 2 scalpellate acrostichals in centre of scutum. Dorsocentrals in single row, prealars few, scutellars in single row. Humeral pit small. Antepronotal lobes developed, narrowing anteriorly, without gap and bare.

Wing (Fig. 2c). Brachiolum, squama, $\mathrm{R}$ and $\mathrm{R}_{4+5}$ with setae. Other veins without setae. Costa extended. $\mathrm{R}_{4+5}$ ends just above $\mathrm{M}_{3+4}$. Anal lobe squared. Microtrichia visible at $>100 \mathrm{x}$ magnification.

Legs. Mid and hind tibia with long sparse beard, hind femur with keel. Pulvilli absent. Fore tibia with 1 spur, each of mid and hind tibia with 2 spurs. Hind tibia comb developed.

Genitalia (Fig. 2d-e). Gonocoxite narrow and long with few setae. Seminal capsules small, semi-circular, spermathecal ducts without loops. Gonapophysis VIII divided into large ventrolateral lobe covering the base of smaller dorsomesal lobe. Apodeme lobe distinct. Tergite IX divided in 2 crescent-shaped setigerous light patches. Cercus with circular base and pediform extensions. 

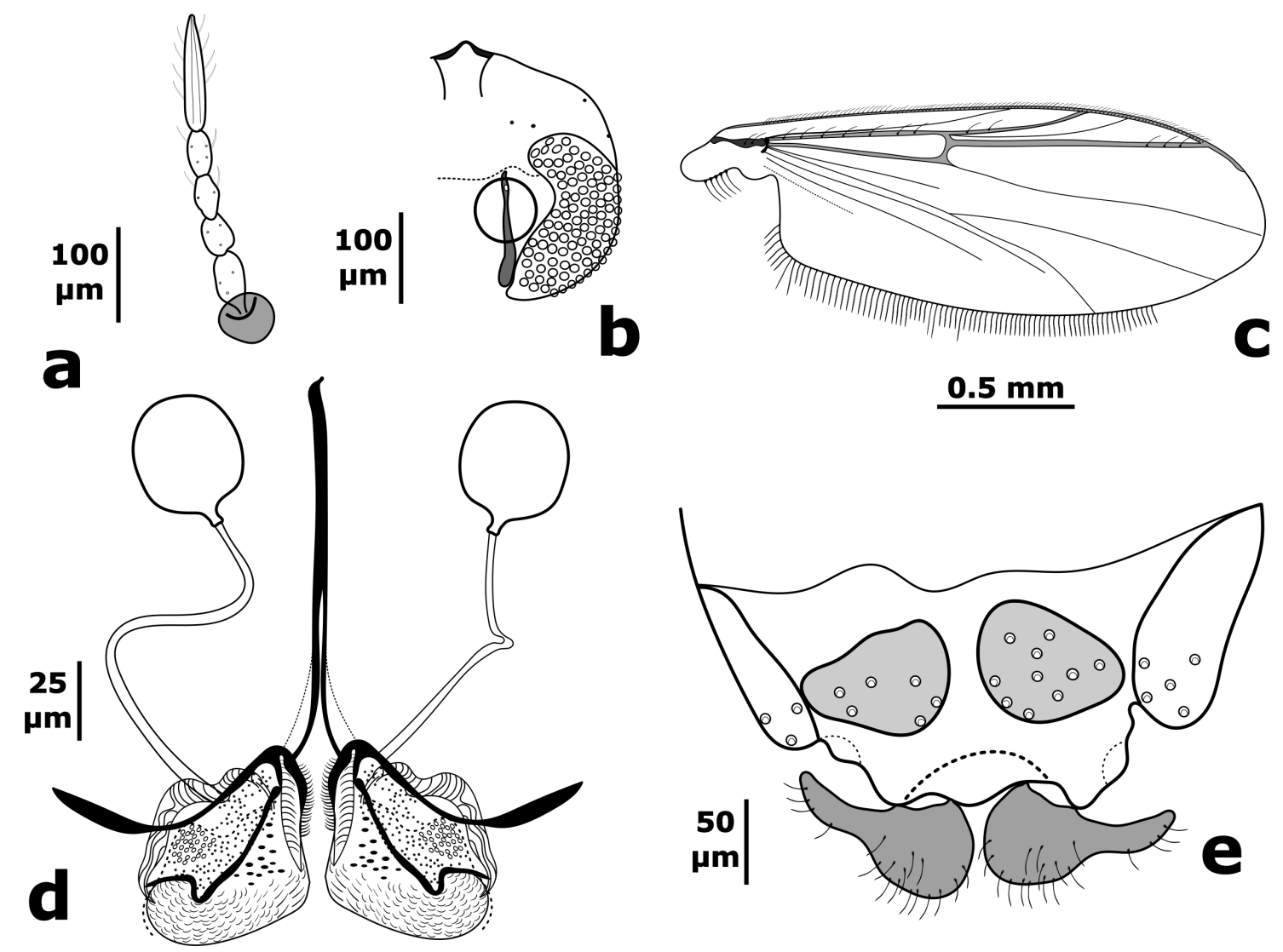

$\underline{0.5 \mathrm{~mm}}$

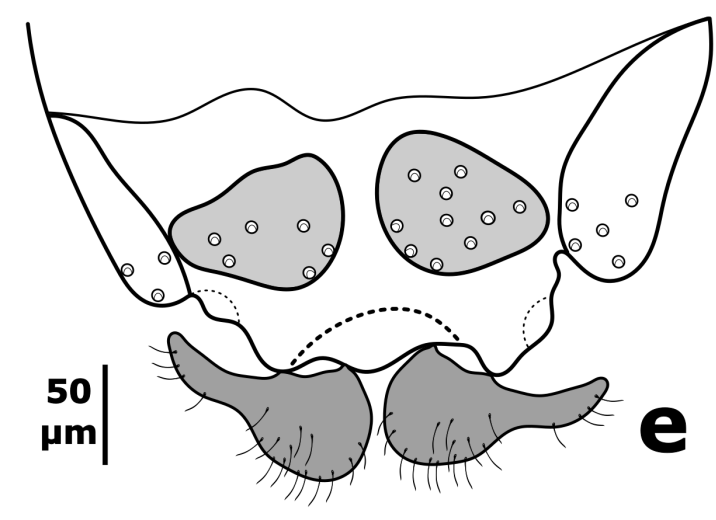

FIGURE 2. Cedrimyia margareti gen. n. sp. n., female. a. antenna; b. head; c. wing; d. genitalia ventral view; e. genitalia, dorsal view.

Remarks. The short and weak anal point setae; long, thin, and blade-like crista dorsalis of gonostylus; and the presence of dorsomedial extension of the eyes are probably autapomorphic in Cedrimyia. The presence of strong, comparatively darker setae on the surface of the Cedrimyia gonostylus can also be considered autapomorphic.

The presence of scalpellate acrostichals on scutum and long anal point of adult males resembles the species in Antillocladius Sæther, 1981, Litocladius Mendes, Andersen \& Sæther, 2004, Lyrocladius Mendes and Andersen, 200, and Compterosmittia Sæther, 1981. The adult male of Cedrimyia can be distinguished from Antillocladius and Litocladius by a combination of short dorsomedial extension of the eye; only 2 scalpellate acrostichals in centre of scutum; short, weak, and posteriorly directed setae of anal point; virga consisting of two long and prominent spines; and thin blade-like crista-dorsalis of the gonostylus. The absence of lateral lamella of virga can further separate adult males of Cedrimyia from Litocladius. The setose squama of Cedrimyia adults can further separate them from Compterosmittia (See Mendes et al. 2004). The presence of strong, comparatively darker setae on the surface of the Cedrimyia gonostylus is also a distinguishing character. Species of Lyrocladius have a laterally located strong setae on their gonostylus. The female of Cedrimyia can be distinguished from Antillocladius by a divided tergite IX with two setigerous protrusions, and a more prominent dorsomesal lobe of gonapophysis IX separates it from Litocladius. In their review of the Orthocladiinae genera with scalpellate acrostichals Mendes and Andersen (2008) placed Antillocladius, Litocladius, and Lyrocladius Mendes and Andersen, 2008 in the same monophyletic group based on the apomorphic characters such as scalpellate acrostichals, and similarity in the shape of anal point and its setation. Cedrimyia likely forms a sister group to this group.

Among other Orthocladiinae, the long anal point with weak lateral setae and the wedge-shaped eye extension bears some resemblance to Paraphaenocladius Thienemann, 1924. A longitudinal ridge on tergite IX of adult males may resemble the species in Tavastia Tuiskunen, 1985, and Mesosmittia Brundin, 1956. Bare eye, absence of apical setae on the last antennal flagellomere, and bare wing of the adults separate Cedrimyia from those of Tavastia. The presence of scalpellate acrostichals in centre of scutum and a more prominent anal point separates Cedrimyia from those of Mesosmittia. 


\section{Cedrimyia margareti sp. nov.}

Type material. Holotype Ȯ; 24.III.2010; USA, Ohio, Hocking Co., Hocking Hills State Park, Queer Creek below Cedar Falls; 39.4194, -82.5269; leg. Patrick Hudson; deposited at ARC. Paratype $3 \hat{\delta} \delta$ same as the holotype. Paratype 1ठ; 16.X.1990; USA, Wisconsin, Douglas Co., Superior Harbor, East End of Lake Superior; 46.691, -91.985; leg. Patrick Hudson; deposited at ARC. Paratype 2O; 24.III.2010; USA, Ohio, Hocking Co., Hocking Hills State Park, Queer Creek below Cedar Falls; leg. Patrick Hudson; deposited at ARC.

Etymology. The new species is named in honor of Margaret Hudson, who has been a great help in collecting type specimens, making this study possible.

Description. Male $(\mathrm{n}=5)$.

Total length 2.8-3.2, $2.9 \mathrm{~mm}$. Wing $2.3 \mathrm{~mm}$ long and $0.65 \mathrm{~mm}$ wide.

Coloration of mounted specimen. Head, thorax, halter brown. Legs and abdomen light to golden brown. Wing light to golden-brown

Head (Fig. 1a). Antenna with 12 flagellomeres, last flagellomere with 8 sensilla chaetica, $2^{\text {nd }}-3^{\text {rd }}$ segments each with 2 sensilla chaetica, groove starts at $3^{\text {rd }}$ segment, AR 1.3-1.4. Eyes bare, with wedge-shaped dorsomedial extension. Temporal setae 9-10, including 3 inner verticals, 3-4 postoculars and 3-4 outer verticals. Tentorium narrow with small tentorial pit close to apex (Fig. 1a), tentorium 135-156, $146 \mu \mathrm{m}$ long. Clypeus rectangular, $87 \mu \mathrm{m}$ long and $116 \mu \mathrm{m}$ wide, bearing 5-7, 6 setae, setae 77-85, $80 \mu \mathrm{m}$ long. Palpal segments lengths (in $\mu \mathrm{m}$ ): 44-54, 50; $50-61,57 ; 73-99,81 ; 83-90,85 ; 127-156,148$. Third palpomere with 1 sensilla clavata.

Thorax (Fig. 1b). 2 scalpellate acrostichals in centre of scutum. Dorsocentrals 5-7, 6 in single row, prealars 2-3, scutellars 4 in single row. Humeral pit small. Antepronotal lobes developed, narrowing anteriorly, without gap and bare.

Wing (Fig. 1c). Brachiolum with 2 setae. Squama with 5 setae. $\mathrm{R}$ with 5 and $\mathrm{R}_{1}$ apparently bare, other veins without setae. Costa extended, extension $69 \mu \mathrm{m} . \mathrm{R}_{4+5}$ ends just above $\mathrm{M}_{3+4}$. Anal lobe squared. Microtrichia visible at $>100 \mathrm{x}$ magnification.

Legs. Mid and hind tibia with long sparse beard, hind femur with keel. Pulvilli absent. Fore tibia spur 43-53, $47 \mu \mathrm{m}$ long, mid tibia spurs $24-25 ; 18-23,20 \mu \mathrm{m}$ long, hind tibia spurs 44-51, 48 and $15 \mu \mathrm{m}$ long, hind tibia comb with around 12 spines. Lengths and proportions of legs as in Table 1.

TABLE 1. Male leg lengths $(\mu \mathrm{m})$ and proportions of Cedrimyia margareti gen. n. sp. n.

\begin{tabular}{llllllllllll}
\hline & $\mathrm{fe}$ & $\mathrm{ti}$ & $\mathrm{ta}_{1}$ & $\mathrm{ta}_{2}$ & $\mathrm{ta}_{3}$ & $\mathrm{ta}_{4}$ & $\mathrm{ta}_{5}$ & $\mathrm{LR}$ & $\mathrm{BV}$ & $\mathrm{SV}$ & $\mathrm{BR}$ \\
\hline $\mathrm{p}_{1}$ & 673 & 811 & 485 & 303 & 228 & 134 & 81 & 0.60 & 2.6 & 3.1 & 1.4 \\
$\mathrm{p}_{2}$ & 683 & 658 & 320 & 174 & 158 & 84 & 75 & 0.49 & 3.4 & 4.2 & 2.3 \\
$\mathrm{p}_{3}$ & 793 & 819 & 410 & 238 & 212 & 120 & 90 & 0.50 & 3.1 & 3.9 & 4.0 \\
\hline
\end{tabular}

Hypopygium (Fig. 1d). Tergite IX with curved ridge running close to mid-section of anal point. Anal point narrowly triangular, long, reaching close to the apex of inferior volsella, bearing around 6 simple, short, and weak setae, distributed evenly along its mid-section, and pointing posteriorly, apex rounded; anal point 75-97, $84 \mu \mathrm{m}$ long and $27-32,29 \mu \mathrm{m}$ wide. Virga present consists of two long spines, 50-54, $53 \mu \mathrm{m}$ long. Sternapodeme straight and thick, $65-73,69 \mu \mathrm{m}$ long. Phallapodeme collar bone-shaped, 72-86, $81 \mu \mathrm{m}$ long. Inferior volsella a prominent triangular lobe. Gonostylus squat-shaped, well expanded in mid to anterior section, surface with 3-4 strong, comparatively darker, spine-like setae; crista dorsalis developed, thin and blade-like, stretching from mid to anterior of gonostylus; gonostylus 65-75, $69 \mu \mathrm{m}$ long. Gonocoxite 181-194, $188 \mu \mathrm{m}$ long. HR 3, HV 3.

Female $(\mathrm{n}=2)$.

Total length 2.0-2.1 mm. Wing 2.1-2.4, $2.2 \mathrm{~mm}$ long and 0.76-0.86, $0.80 \mathrm{~mm}$ wide.

Coloration of mounted specimen. Head, thorax, halter brown. Legs and abdomen light to golden brown. Wing light to golden-brown

Head (Fig. 2a-b). Antenna with 5 flagellomeres, last flagellomere with 10 sensilla chaetica, $3^{\text {rd }}-4^{\text {th }}$ segments each with 2 sensilla chaetica (Fig. 2a), AR 0.5-0.6. Eyes bare, with short dorsomedial extension. Temporal setae 5, including 1 inner verticals, 1 postoculars, 2 orbitals and 1 outer verticals (Fig. 2b). Tentorium long and narrow with small tentorial pit close to apex, tentorium 126-149, $137 \mu \mathrm{m}$ long. Clypeus rectangular, $89 \mu \mathrm{m}$ long and 109-127, $118 \mu \mathrm{m}$ wide, bearing $5 \mathrm{setae}$, setae $88 \mu \mathrm{m}$ long. Palpal segments lengths (in $\mu \mathrm{m}$ ): 44-52, 48; 49-55, 52; 82-84, 83; 77-84, 80; 138-154, 146. Third palpomere with 1 sensilla clavata. 
Thorax. 2 scalpellate acrostichals in centre of scutum. Dorsocentrals 5-6 in single row, prealars 2, scutellars 4 in single row. Humeral pit small. Antepronotal lobes developed, narrowing anteriorly, without gap and bare.

Wing (Fig. 2c). Brachiolum with 2 setae. Squama with 5 setae. $\mathrm{R}$ with $6-10,8, \mathrm{R}_{1}$ with $2-3$ setae, $\mathrm{R}_{4+5}$ with $2-3$ setae, other veins without setae. Costa extended, extension $137 \mu \mathrm{m} . \mathrm{R}_{4+5}$ ends just above $\mathrm{M}_{3+4}$. Anal lobe squared. Microtrichia visible at $>100 \times$ magnification.

Legs. Mid and hind tibia with long sparse beard, hind femur with keel. Pulvilli absent. Fore tibia spur 22-30 (26) $\mu \mathrm{m}$ long, mid tibia spurs 22-25, 23; 21-22 $\mu \mathrm{m}$ long, hind tibia spurs 38-52, 45 and $22 \mu \mathrm{m}$ long, hind tibia comb with around 12 spines. Lengths and proportions of legs as in Table 2.

TABLE 2. Female leg lengths $(\mu \mathrm{m})$ and proportions of Cedrimyia margareti gen. n. sp. n.

\begin{tabular}{llllllllllll}
\hline & $\mathrm{fe}$ & $\mathrm{ti}$ & $\mathrm{ta}_{1}$ & $\mathrm{ta}_{2}$ & $\mathrm{ta}_{3}$ & $\mathrm{ta}_{4}$ & $\mathrm{ta}_{5}$ & $\mathrm{LR}$ & $\mathrm{BV}$ & $\mathrm{SV}$ & $\mathrm{BR}$ \\
\hline $\mathrm{p}_{1}$ & 598 & 677 & 389 & 220 & 155 & 94 & 80 & 0.57 & 3.0 & 3.3 & 0.9 \\
$\mathrm{p}_{2}$ & 623 & 558 & 254 & 154 & 91 & 68 & 76 & 0.45 & 3.7 & 4.7 & 1.3 \\
$\mathrm{p}_{3}$ & 725 & 749 & 385 & 198 & 91 & 88 & 67 & 0.51 & 4.2 & 3.8 & 1.1 \\
\hline
\end{tabular}

Genitalia (Fig. 2d-e). Gonocoxite narrow and long with 4 setae. Seminal capsules small, semi-circular, spermathecal ducts without loops (Fig. 2d), seminal capsule 35-46, $40 \mu \mathrm{m}$ long, $31 \mu \mathrm{m}$ wide. Notum $174 \mu \mathrm{m}$ long. Gonapophysis VIII divided into large ventrolateral lobe covering the base of smaller dorsomesal lobe. Apodeme lobe distinct. Tergite IX divided in 2 crescent-shaped setigerous light patches (Fig. 2e). Cercus with circular base and pediform extensions (Fig. 2e), $117 \mu \mathrm{m}$ long and 43-55, $49 \mu \mathrm{m}$ wide.

Ecology and habitat. Adults of the species were collected in the vicinity of Queer Creek just below Cedar Falls and along Superior Harbor in Lake Superior, vastly different habitats. Queer Creek is a third-order stream running through a deep ravine with rugged sandstone cliffs covered in part with lichen and with numerous seeps. Superior Harbor is part of a highly modified St. Louis River estuary for maintaining a safe harbor for both Great Lakes and international shipping. Extrapolating from these suggests that the habitat for this new genus is probably not truly aquatic but is presumably decaying moist organic matter along the shores of these two habitats. It is likely that the high organic (humus) soil of this region provides an ideal habitat for terrestrial Chironomidae. In East Fork Queer Creek, Ohio, close to our sampling location, Bolton and Jacobsen (2010) previously found close to seven species of terrestrial Chironomidae. The presence of emerging adults in May and again in October indicates that this species has more than one voltine.

\section{Parakiefferiella mishigami sp. nov.}

Fig. 3

LSID: urn:1sid:zoobank.org:act:33D7B56A-63BF-4F0E-88B5-DDD24DC2C870

Type material. Holotype ふ̋; 19.V.1991; USA, Michigan, Chippawa Co., Neebish Island, St. Marys River, Downbound channel; 46.292, -84.218; leg. Patrick Hudson; deposited at ARC.

Diagnostic characters. The new species can be separated from other Parakiefferiella species by a combination of the following characters: AR 1.1; costa of wing not well-extended; LR $_{1}$ 0.42; anal point shallow, broadly triangular; virga with two short spines; inferior volsella bilobed with dorsal lobe smaller, anterior to a larger, roundly projecting ventral lobe.

Etymology. The new species is named after the state of Michigan. The name mishigami is Ojibwe, meaning a "large lake".

Description. Male $(\mathrm{n}=1)$.

Total length $2.9 \mathrm{~mm}$. Wing $2.1 \mathrm{~mm}$ long and $0.51 \mathrm{~mm}$ wide. 

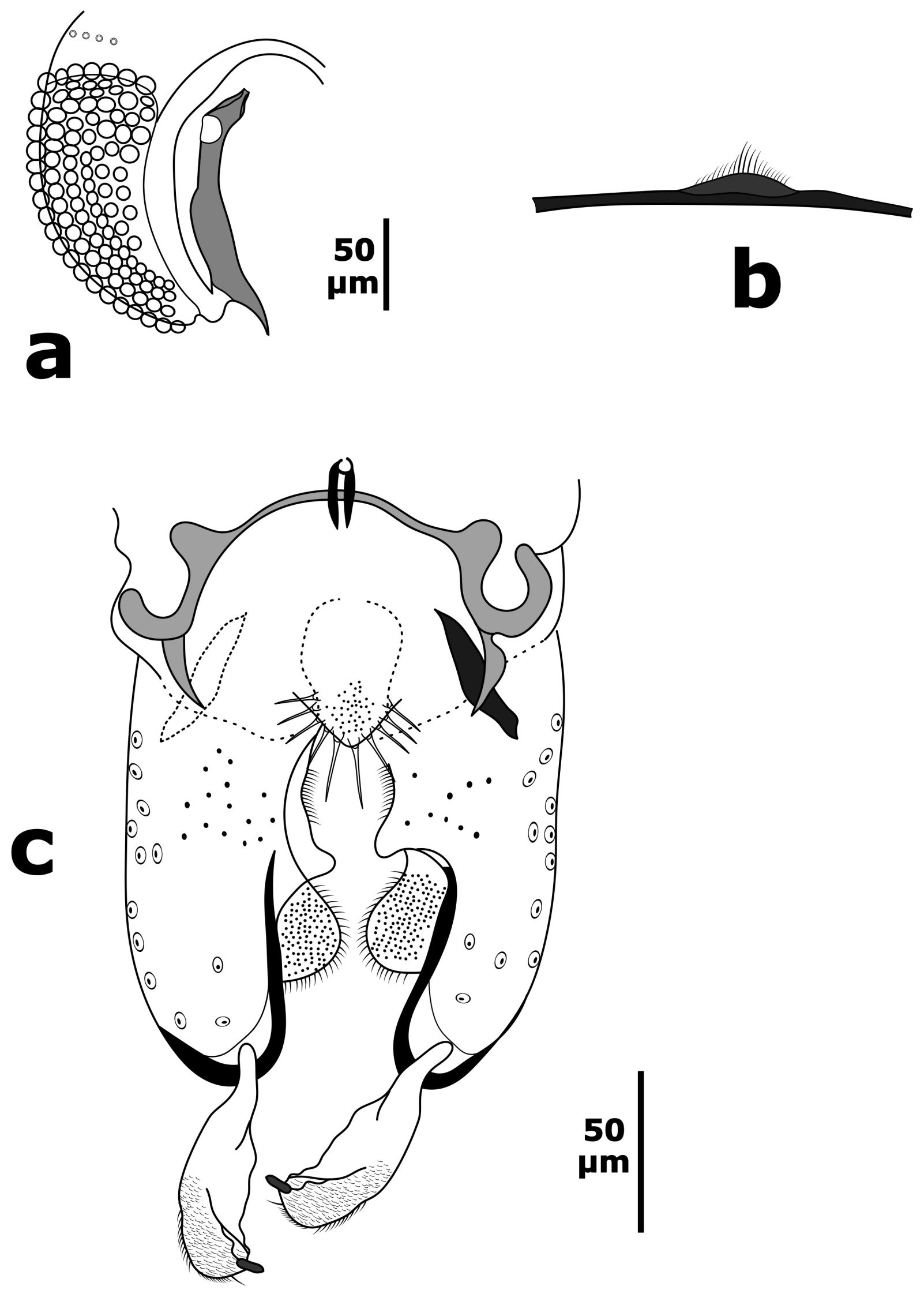

FIGURE 3. Parakiefferiella mishigami sp. nov., male. a. head; b. centre of scutum tuft of setae; c. hypopygium. 
Coloration of mounted specimen. Head, thorax, halter and tergites brown. Legs and sternites light brown. Wing greyish-brown

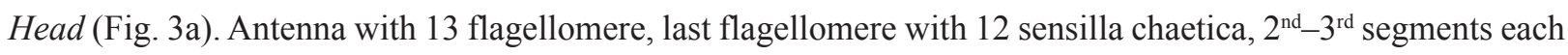
with 2 sensilla chaetica, groove starts at $4^{\text {th }}$ segment, AR 1.1. Eyes bare, without dorsomedial extension, temporal setae with 4 inner verticals in single row (Fig. 3a). Tentorium narrow with large tentorial pit close to apex (Fig. 3a), tentorium $141 \mu \mathrm{m}$ long. Clypeus rectangular, $71 \mu \mathrm{m}$ long and $123 \mu \mathrm{m}$ wide, bearing 7 setae, setae 59-77, $67 \mu \mathrm{m}$ long. Palpal segments lengths (in $\mu \mathrm{m}$ ): 56, 37, 80, 83, 117.

Thorax. Dorsocentrals 5, prealars 4, scutellars 6 in single row. Median tuft of setae in centre of scutum (Fig. 3b). Humeral pit vestigial. Antepronotal lobes developed, narrowing anteriorly, with small gap and bearing 3 setae.

Wing. Brachiolum bare. Squama bare. $\mathrm{R}$ and $\mathrm{R}_{1}$ apparently bare, other veins without setae. Costa not well-extended. Anal lobe rounded. Fine punctation visible at $40 \mathrm{x}$ magnification.

Legs. Femur and tibia of all legs with long beard. Pulvilli vestigial. Fore tibia spur $40 \mu \mathrm{m}$ long, mid tibia spurs $11 \mu \mathrm{m}$ long, hind tibia spurs 38 and $15 \mu \mathrm{m}$ long, hind tibia comb with around 18 spines. Lengths and proportions of legs as in Table 3.

TABLE 3. Male leg lengths $(\mu \mathrm{m})$ and proportions of Parakiefferiella mishigami sp. nov.

\begin{tabular}{llllllllllll}
\hline & $\mathrm{fe}$ & $\mathrm{ti}$ & $\mathrm{ta}_{1}$ & $\mathrm{ta}_{2}$ & $\mathrm{ta}_{3}$ & $\mathrm{ta}_{4}$ & $\mathrm{ta}_{5}$ & $\mathrm{LR}$ & $\mathrm{BV}$ & $\mathrm{SV}$ & $\mathrm{BR}$ \\
\hline $\mathrm{p}_{1}$ & 535 & 726 & 303 & 161 & 119 & 82 & 83 & 0.42 & 3.5 & 4.2 & 2.1 \\
$\mathrm{p}_{2}$ & 679 & 690 & - & - & - & - & - & - & - & - & - \\
$\mathrm{p}_{3}$ & 638 & 709 & - & - & - & - & - & - & - & - & - \\
\hline
\end{tabular}

Hypopygium (Fig. 3c). Anal point shallow, broadly triangular, bearing around 10 simple setae, anal point 20 $\mu \mathrm{m}$ long and $46 \mu \mathrm{m}$ wide. Virga consists of two spines, $21 \mu \mathrm{m}$ long. Sternapodeme slightly arched with large oral projections, sternapodeme $98 \mu \mathrm{m}$ long. Phallapodeme large, $51 \mu \mathrm{m}$ long. Inferior volsella consist of two lobes, the dorsal lobe smaller, digitiform, located anteriad to the larger, roundly projecting ventral lobe. Gonostylus bent, tapered posteriorly, gradually expanding anteriorly, gonostylus $82 \mu \mathrm{m}$ long, crista dorsalis receded. Gonocoxite 193 $\mu \mathrm{m}$ long. HR 2.3, HV 3.4.

Remarks. Combination of a tuft of setae in centre of scutum, eyes bare and without dorsomedial extension, a bare wing with bare squama, and vestigial pulvilli places this specimen in Parakiefferiella. This species can be separated from the species of Epoicocladius Zavřel, 1924 based on its relatively short apical palpal segment and a median bent in its gonostylus. The presence of a well-separated bilobed inferior volsella can be seen in some species of Parakiefferiella, more prominently in Parakiefferiella bilobata Tuiskunen 1986. However, P. mishigami differs from these species in that the posterior lobe is much more prominent than the anterior lobe, and it also differs in shape.

Ecology and habitat. The single adult collected in the vicinity of St. Marys River, Michigan, suggesting the larvae inhabiting large running waters.

\section{Acknowledgments}

Our sincere thanks to Dr. Broughton Caldwell for providing voucher specimens of Antillocladius for points of morphological comparison. Many thanks to two anonymous reviewers whose comments and corrections greatly improved this article. Our sincere thanks to Dr. Anthony Cognato, Director of the A. J. Cook Arthropod Research Collection, Michigan State University for help in housing the type specimens.

\section{References}

Bolton, M.J. (2012) Ohio EPA supplemental keys to the larval Chironomidae (Diptera) of Ohio and Ohio Chironomidae checklist. Ohio Environmental Protection Agency, Division of Surface Water, Columbus, Ohio. 111 p.

Bolton, M.J. \& Jacobsen, R.E. (2010) The immature stages of Chasmatonotus unimaculatus Loew (Diptera: Chironomidae: Orthocladiinae) with notes on their habitat. In: Ferrington Jr., L.C. (Ed.), Proceedings of the XV International Symposium on Chironomidae, St. Paul, Minnesota, 12-14 August 2003. University of Minnesota, St. Paul, Minnesota, pp. $255-261$. 
Bright, E. (2020) Aquatic Insects of Michigan. Chironomidae Newman, 1834: 379-Non-biting midges. Available from: http:// www.aquaticinsects.org/sp/Diptera/sp_dom_chir.html/ (accessed 2 July 2021)

Egan, A.T. \& Ferrington, L.C. (2019) Chironomidae of the Upper Saint Croix River, Wisconsin. Transactions of the American Entomological Society, 145, 353-384. https://doi.org/10.3157/061.145.0307

Ferrington, L.C. (2008) Global diversity of non-biting midges (Chironomidae; Insecta-Diptera) in freshwater. In: Balian, E.V., Lévêque, C., Segers, H. \& Martens, K. (Eds.), Freshwater Animal Diversity Assessment. Springer, Dordrecht, pp. 447455. https://doi.org/10.1007/s10750-007-9130-1

Hudson, P.L., Lenat, D.R., Caldwell, B.A. \& Smith, D. (1990) Chironomidae of the Southeastern United States: a checklist of species and notes on biology, distribution, and habitat. Fish and Wildlife Research, 7, 1-46.

Mendes, H.F., Andersen, T. \& Sæther, O.A. (2004) A review of Antillocladius Sæther, 1981; Compterosmittia Sæther, 1981 and Litocladius new genus (Chironomidae, Orthocladiinae). Zootaxa, 594, 1-82. https://doi.org/10.11646/zootaxa.594.1.1

Mendes, H.F. \& Andersen, T. (2008) A review of Antillocladius Sæther and Litocladius Mendes, Andersen et Sæther, with the description of two new Neotropical genera (Diptera, Chironomidae, Orthocladiinae). Zootaxa, 1887 (1), 1-75. https://doi.org/10.11646/zootaxa.1887.1.1

Saether, O.A. (1977) Female genitalia in Chironomidae and other Nematocera: morphology, phylogenies, keys. Bulletin of the Fisheries Research Board of Canada, 197, 1-220.

Saether, O.A. (1980) Glossary of chironomid morphology terminology (Diptera: Chironomidae). Entomologica Scandinavica Supplement, 14, 1-51. 